\title{
Airway antioxidant and inflammatory responses to diesel exhaust exposure in healthy humans
}

\author{
A.F. Behndig*, $f$ I.S. Mudway*,,$f$, J.L. Brown\#, N. Stenfors*, R. Helleday*, \\ S.T. Duggan , S.J. Wilson\#, C. Boman ${ }^{+}$, F.R. Cassee ${ }^{\S}$, A.J. Frew ${ }^{\#}$, F.J. Kelly \\ T. Sandström* and A. Blomberg*
}

ABSTRACT: Pulmonary cells exposed to diesel exhaust (DE) particles in vitro respond in a hierarchical fashion with protective antioxidant responses predominating at low doses and inflammation and injury only occurring at higher concentrations. In the present study, the authors examined whether similar responses occurred in vivo, specifically whether antioxidants were upregulated following a low-dose DE challenge and investigated how these responses related to the development of airway inflammation at different levels of the respiratory tract where particle dose varies markedly.

A total of 15 volunteers were exposed to DE $\left(100 \mu \mathrm{g} \cdot \mathrm{m}^{-3}\right.$ airborne particulate matter with a diameter of $<10 \mu \mathrm{m}$ for $2 \mathrm{~h}$ ) and air in a double-blinded, randomised fashion. At $18 \mathrm{~h}$ postexposure, bronchoscopy was performed with lavage and mucosal biopsies taken to assess airway redox and inflammatory status.

Following DE exposure, the current authors observed an increase in bronchial mucosa neutrophil and mast cell numbers, as well as increased neutrophil numbers, interleukin-8 and myeloperoxidase concentrations in bronchial lavage. No inflammatory responses were seen in the alveolar compartment, but both reduced glutathione and urate concentrations were increased following diesel exposure.

In conclusion, the lung inflammatory response to diesel exhaust is compartmentalised, related to differing antioxidant responses in the conducting airway and alveolar regions.

KEYWORDS: Air pollution, airway inflammation, antioxidants, diesel exhaust, glutathione, particulate matter

$\mathbf{T}$ ime-series studies demonstrate that shortterm increases in ambient particle concentrations are associated with hospital admissions [1] and deaths from respiratory and cardiovascular disorders [2, 3]. In urban areas, motor vehicles can contribute to $25-35 \%$ of total airborne particulate matter (PM) with a diameter of $<2.5 \mu \mathrm{m}$ (PM2.5) [4, 5], with concentrations near busy roads up to $30 \%$ greater than background levels. Numerous studies have examined the relationship between exposure to motor vehicle emissions and respiratory health [6-14] with recent evidence demonstrating that children living near busy roads have an increased prevalence of chronic respiratory symptoms $[7,8,13$, 14]. Whilst the majority of these studies have been unable to single out specific traffic components associated with the measured health effects, some studies utilising automated traffic counts have concluded that symptoms are associated with heavy, predominantly diesel-powered vehicles $[7,8,13]$.

Whilst the biological mechanisms underlying these health effects are poorly understood, emerging data suggest that the capacity of particles to cause inflammation via the induction of oxidative stress is important. In this scenario, particles activate redox sensitive transcription factors, promoting the transcription of pro-inflammatory cytokines [15]. This capacity to cause oxidative stress appears to be related to the presence of oxidants or oxidant-generating components on the particle surface. Consistent with this view, diesel particles have been shown to contain redox-cycling quinones [16], polycyclic aromatic hydrocarbons (PAHs) [16] and transition metals capable of catalysing oxidation reactions $[17,18]$.
AFFILIATIONS

*Dept of Respiratory Medicine and Allergy, University Hospital, and +Energy Technology and Thermal Process Chemistry, Umeå University, Umeå, Sweden.

\#Respiratory Cell and Molecular Biology Research Division, Southampton General Hospital, Southampton, and "Lung Biology, Pharmacology and Therapeutics, Pharmaceutical Sciences Research Division, Franklin-Wilkins Building, King's College London, London, UK ${ }^{\text {s }}$ Centre for Environmental Health Research, National Institute of Public Health and the Environment (RIVM) Bilthoven, The Netherlands. ${ }^{\dagger}$ Equal contribution to first authorship.

CORRESPONDENCE

T. Sandström

Dept of Respiratory Medicine and

Allergy

University Hospital

SE-901 85 Umeå

Sweden

Fax: 4690141369

E-mail:

thomas.sandstrom@lung.umu.se

Received:

November 302004

Accepted after revision:

September 152005

SUPPORT STATEMENT

The authors would like to acknowledge the support received from the Swedish Heart-Lung Foundation, European Commission Health Effects of Particles from Motor Engine Exhaust and Ambient Air project (QLRT 1999-01582) and Umeå University, Sweden.

European Respiratory Journal Print ISSN 0903-1936 
Furthermore, reactive oxygen species have been detected in airway epithelial cells exposed to diesel exhaust particles (DEP) or their organic extracts $[19,20]$.

DEP and their organic components have been shown to upregulate pro-inflammatory cytokines in macrophage and bronchial epithelial cell lines [21-23], and to trigger neutrophilic inflammation in laboratory animals [24-26] and humans [27-34] exposed to diesel exhaust (DE). Consistent with the oxidative stress hypothesis, treatment of epithelial cells and macrophages with antioxidants has been shown to reduce particle-induced cytokine production through the downregulation of redox-sensitive signalling pathways [25, 26]. The importance of antioxidants in modulating the inflammatory response to particles has also been demonstrated by the upregulation of endogenous antioxidant defences including: reduced glutathione [17, 35], haem oxygenase-1 [23], catalase, metallothionein [36] and glutathione reductase [35]. XIAO et al. [36] have proposed that a response hierarchy exists in cells exposed to diesel particles, with low concentrations stimulating protective antioxidant responses, and inflammation and injury only occurring at higher concentrations once endogenous defences have been overwhelmed.

Previous human exposure studies examining the capacity of inhaled particles (concentrated ambient particles [32-34], resuspended DEP [31] and fresh DE [27-29]) to elicit inflammation have yielded somewhat inconclusive findings, with evidence of airway inflammation at high particle concentrations [28, 33], but with less clear-cut responses to lower dose exposures $[29,34]$. In the current study, the authors examined inflammatory and antioxidant responses in healthy volunteers exposed to a low-dose diesel inhalation challenge. Under question was whether the attenuated inflammatory responses reported with the low-dose exposures could be related to an upregulation of endogenous antioxidant defences. By examining the responses in the bronchial airways and alveoli it was possible to investigate the balance between antioxidant and inflammatory processes at sites experiencing significantly different tissue doses of particles. Hence, two tissue-dose scenarios could be investigated in a single inhalation study.

\section{METHODS}

\section{Experimental exposure and particle characterisation}

DE was generated using an idling Volvo diesel engine (Volvo TD45, 4.5 L, four cylinders, $680 \mathrm{r} \cdot \mathrm{min}^{-1}$, model 1991; Volvo, Gottenburg, Sweden) as previously described [27, 29]. The steady state concentration of PM10, gases and semi-volatiles during the diesel exposures were $100 \pm 4.9 \mu \mathrm{g} \cdot \mathrm{m}^{-3}$ (PM10), $10.4 \pm 1.7$ parts per million (ppm; carbon monoxide), $1.3 \pm 0.04 \mathrm{ppm}$ (nitrogen monoxide), $0.4 \pm 0.02 \mathrm{ppm}$ (nitrogen dioxide), $1.8 \pm 0.03 \mathrm{ppm}$ (oxides of nitrogen) and $1.3 \pm 0.49 \mathrm{ppm}$ (total gaseous hydrocarbons: $\mathrm{C}_{3} \mathrm{H}_{8}$-equivalents), expressed as mean $\pm S D$.

The PM mass in the exposure chamber was dominated by fine particles $(<1 \mu \mathrm{m})$ in the accumulation mode, with a mass median particle diameter for the sub-micrometer sized PM of $0.18 \mu \mathrm{m}$. Quartz fibre filters were used to sample PAHs on particles. A polyurethane foam plug was used for collecting semi-volatile compounds. A total of 45 specific PAH compounds were analysed by gas chromatography-mass spectrometry. Elemental composition of the fine particle fraction was assessed using inductively coupled plasma-mass spectroscopy.

\section{Subjects}

In total, 15 healthy volunteers (seven female and eight male) with a mean age of 24 yrs were recruited. They were all neversmokers with normal lung function and negative skin-prick tests (table 1). No anti-inflammatory or other drugs, including antioxidant supplements, were permitted for the duration of the study. All participants gave informed written consent and the local ethics committee (Umeå University, Umeå, Sweden) approved the study.

\section{Exposure protocol}

Each subject was exposed to diluted DE with a particulate concentration (total PM) of $100 \mu \mathrm{g} \cdot \mathrm{m}^{-3}$ and filtered air for $2 \mathrm{~h}$ in a specially built exposure chamber as previously described [27, 28]. The exposures took place on two separate occasions, in a randomised sequence, $\geqslant 3$ weeks apart. The subjects were blinded to the actual exposure. Challenge dates were rescheduled if subjects experienced any form of respiratory infection within a 6-week period prior to scheduled exposure date. During the exposures subjects alternated between 15-min intervals of exercise (minute ventilation $=20 \mathrm{~L} \cdot \mathrm{min}^{-1} \cdot \mathrm{m}^{-2}$ body surface area) and rest, to model a moderate level of outdoor activity. Exercise was performed using a bicycle ergometer situated within the exposure chamber.

\section{Bronchoscopy and processing of samples}

Bronchoscopy was performed $18 \mathrm{~h}$ post-exposure, as previously described, using a flexible video bronchoscope (Olympus BF IT200; Olympus, Tokyo, Japan) [28, 29]. Bronchial biopsies were taken from proximal cristae. Bronchial wash (BW;

\begin{tabular}{|c|c|c|c|c|c|c|c|}
\hline Subject & Sex & $\begin{array}{l}\text { Age } \\
\text { yrs }\end{array}$ & $\begin{array}{c}\text { Height } \\
\text { cm }\end{array}$ & $\begin{array}{c}\text { Weight } \\
\text { kg }\end{array}$ & $\begin{array}{c}\text { FVC } \\
\text { L }\end{array}$ & $\begin{array}{c}\text { FEV } 1 \\
\text { L }\end{array}$ & $\begin{array}{c}\text { FEV1 } \\
\% \text { pred }\end{array}$ \\
\hline 1 & $M$ & 22 & 181 & 72 & 4.9 & 4.3 & 87 \\
\hline 2 & M & 23 & 176 & 69 & 4.2 & 4.1 & 87 \\
\hline 3 & $\mathrm{~F}$ & 24 & 171 & 61 & 3.9 & 3.5 & 94 \\
\hline 4 & $M$ & 25 & 195 & 92 & 5.8 & 4.6 & 86 \\
\hline 5 & $M$ & 23 & 183 & 80 & 5.2 & 4.4 & 88 \\
\hline 6 & M & 27 & 180 & 79 & 5.8 & 5.1 & 107 \\
\hline 7 & $\mathrm{~F}$ & 21 & 162 & 67 & 3.0 & 2.9 & 83 \\
\hline 8 & $\mathrm{~F}$ & 22 & 168 & 66 & 4.0 & 3.8 & 106 \\
\hline 9 & $\mathrm{~F}$ & 27 & 152 & 49 & 2.9 & 2.7 & 87 \\
\hline 10 & $\mathrm{~F}$ & 26 & 164 & 62 & 4.0 & 3.8 & 110 \\
\hline 11 & $\mathrm{~F}$ & 27 & 158 & 63 & 3.5 & 3.2 & 99 \\
\hline 12 & $\mathrm{~F}$ & 23 & 158 & 59 & 3.8 & 3.4 & 101 \\
\hline 13 & M & 24 & 181 & 82 & 5.2 & 4.5 & 92 \\
\hline 14 & $M$ & 26 & 177 & 76 & 5.3 & 4.9 & 103 \\
\hline 15 & M & 21 & 178 & 71 & 5.2 & 5.0 & 103 \\
\hline Mean $\pm S D$ & & $24 \pm 2$ & $172 \pm 12$ & $70 \pm 11$ & $4.4 \pm 1$ & $4.0 \pm 0.8$ & $96 \pm 9$ \\
\hline
\end{tabular}


$2 \times 20 \mathrm{~mL}$ ) and bronchoalveolar lavage (BAL; $3 \times 60 \mathrm{~mL}$ ) were carried out in the contra-lateral lung. The aspirates recovered from the first and second $20 \mathrm{~mL}$ instillations of the $\mathrm{BW}$ and the pooled BAL were collected into separate siliconised containers and immediately placed on ice. All lavage samples were filtered through nylon (pore diameter $=100 \mu \mathrm{m}$ ) and centrifuged at $400 \mathrm{~g}$ for $15 \mathrm{~min}$. The supernatants were separated from the cell pellet and analysed for albumin, total protein, interleukin (IL)-6, IL-8 and myeloperoxidase (MPO). Cell pellets were resuspended in PBS at a cell concentration of $10^{6}$ cells $\cdot \mathrm{mL}^{-1}$. Differential cell counts were performed on cyto-centrifuge preparations stained with May-Grünwald Giemsa and 400 cells per slide were counted. IL-6 and IL-8 were measured using commercially available ELISA kits (R\&D Systems, Inc., Minneapolis, MN, USA). MPO was analysed using an MPO radio-immunoassay (Pharmacia AB, Uppsala, Sweden).

\section{Lung function tests}

Standard lung function tests, forced vital capacity and forced expiratory capacity in one second were performed at inclusion using a spirometer (Vitalograph R, Buckingham, UK).

\section{Immunohistochemistry}

Mucosal biopsies were processed into glycolmethacrylate resin, as previously described [28]. Sections $(2 \mu \mathrm{m})$ were cut and stained immunohistochemically using the streptavidin biotin-peroxidase technique with monoclonal antibodies $(\mathrm{mAb})$ directed against specific cellular markers to detect inflammatory cells in the bronchial mucosa.

Stained inflammatory cells were counted in the epithelium and submucosa excluding glands, blood vessels and muscle. The counts were expressed as cells $\cdot \mathrm{mm}^{-1}$ in the epithelium and cells $\cdot \mathrm{mm}^{-2}$ in the submucosa and counted using a light microscope. The length of the epithelium and the area of the submucosa were calculated using a computer-assisted image analyser (Zeiss KS400 software; Image Associates, Bicester, UK). Endothelial adhesion molecules (P-selectin, E-selectin, vascular adhesion molecule (VCAM)-1 and intracellular adhesion molecule (ICAM)-1) in the vessels were quantified by expressing the number of vessels stained with specific $\mathrm{mAb}$ as a percentage of the total number of blood vessels stained with the pan-endothelial mAb EN4 in adjacent 2- $\mu \mathrm{m}$ sections.

\section{Antioxidant determinations}

Reduced glutathione (GSH) and oxidised glutathione (GSSG) were measured using the GSSG reductase-5,5'-dithiobis(2nitrobenzoic acid) recycling assay as described previously [17]. Vitamin C (ascorbate+dehydroascorbate) and urate concentrations were determined using reverse phase HPLC with electrochemical detection, as outlined previously [17], following sample reduction with dithiothreitol.

\section{Permeability and cellular injury marker determinations}

Albumin concentrations were measured using a commercial kit (Boehringer-Mannheim, Mannheim, Germany). Total protein determinations were made using the bicinchoninic acid method. DNA concentrations were determined using bisbenzimadazole (Hoechst 33258; Sigma, Poole, UK) according to established protocols [17].

\section{Statistical analysis}

All data were nonparametric and are therefore described throughout using medians with 25th and 75th percentiles. Comparisons between post-air and diesel values were performed using the Wilcoxon signed-rank test. Correlations between diesel-induced responses were performed using Spearman's rank-order correlation.

\section{RESULTS}

\section{Particle composition}

A total of $64 \%$ of the PM sampled in the DE consisted of carbonaceous material with the major part (94.5\%) present as organic carbon and only $5.5 \%$ as elemental carbon. The major part $(96.5 \%)$ of the PAH consisted of semi-volatile gaseous compounds with only a minor fraction (3.5\%) present as particulate-associated material, $0.04 \%$ of total PM and $0.06 \%$ of the PM organic fraction. The dominating PAHs were phenanthrene, fluorene, 2-methylfluorene, dibenzothiophene and different methyl-substituted phenanthrenes accounting for $\sim 90 \%$ of the total PAH. Of the metals measured in the diesel particle fraction $(\mathrm{Pb}, \mathrm{Al}, \mathrm{Zn}, \mathrm{Cu}, \mathrm{Ni}, \mathrm{Fe}, \mathrm{Mn}, \mathrm{Cr}, \mathrm{V}$ and $\mathrm{Ti})$, only appreciable concentrations of the redox-inactive metals $\mathrm{Al}$ and Zn were detected.

\section{Inflammatory responses}

Following DE exposure, there was a 1.7-fold increase in median neutrophil numbers in the BW compared with postair samples $\left(0.85 \times 10^{4}\right.$ post-air versus $1.41 \times 10^{4}$ cells $\cdot \mathrm{mL}^{-1}$ post$\mathrm{DE} ; \mathrm{p}=0.02)$. All other cell types remained unchanged (table 2). In contrast, no cell changes were detected in the alveolar lavage sample $18 \mathrm{~h}$ after DE exposure (table 2). Immunohistochemical analysis of the bronchial biopsies revealed that DE induced a significant increase in submucosal neutrophils (45.0 post-air versus 65.9 cells $\cdot \mathrm{mm}^{-2}$ post-DEP; $\mathrm{p}=0.01)$ as well as a small increase in submucosal mast cell numbers (13.3 post-air versus 20.1 cells $\cdot \mathrm{mm}^{-2}$ post-DE; $\mathrm{p}=0.02$; table 3). No changes were found in the numbers of eosinophils or lymphocytes (CD3+, CD4+ or CD8+) in the submucosa after DE exposure (table 3). The expression of the vascular endothelial adhesion molecules, P-selectin, E-selectin, ICAM-1

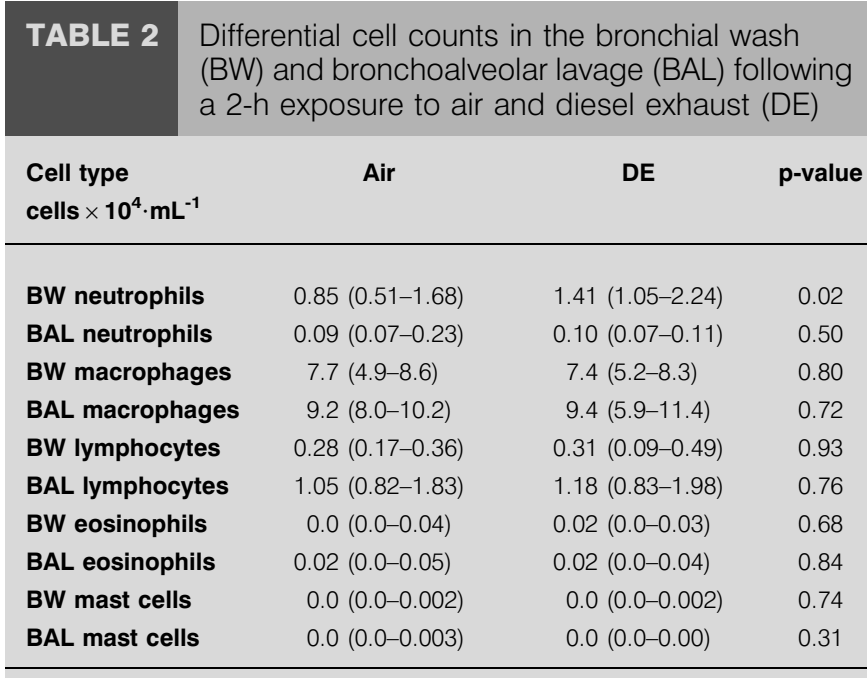

Data are presented as median (interquartile range). $n=15$. 


\begin{tabular}{llcl} 
TABLE 3 & $\begin{array}{l}\text { Inflammatory cells in the bronchial tissue } \\
\text { following a 2-h exposure to air and diesel } \\
\text { exhaust (DE) }\end{array}$ \\
$\begin{array}{l}\text { Inflammatory cells } \\
\text { cells·mm-2 }\end{array}$ & Air & DE & p-value \\
\hline Neutrophils & $45.0(24.7-71.4)$ & $65.9(57.0-118.9)$ & 0.01 \\
Mast cells & $13.3(9.4-20.3)$ & $20.1(15.4-32.8)$ & 0.02 \\
Eosinophils & $0.0(0.0-0.0)$ & $0.0(0.0-0.0)$ & 1.00 \\
CD3+ & $42.1(23.7-57.0)$ & $36.6(30.7-45.0)$ & 0.80 \\
CD4+ & $22.5(16.9-27.8)$ & $18.2(9.5-29.7)$ & 0.39 \\
CD8+ & $14.3(7.0-21.4)$ & $11.8(8.6-17.6)$ & 0.45 \\
\hline \multicolumn{4}{l}{} \\
Data are presented as median (interquartile range). $\mathrm{n}=15$. & \\
&
\end{tabular}

and VCAM-1 were unchanged $18 \mathrm{~h}$ after DE exposure (data not shown). This increase in bronchial airway lumen and submucosal neutrophils after DE was associated with a significant increase in IL-8 protein (35.0 post-air versus $45.0 \mathrm{pg} \cdot \mathrm{mL}^{-1}$ post-DE; $\mathrm{p}=0.01$ ), and MPO (5.1 post-air versus $11.2 \mu \mathrm{g} \cdot \mathrm{L}^{-1}$ post-DE; $\left.\mathrm{p}=0.03\right)$ in the $\mathrm{BW}$ along with a trend toward an increase in the concentration of IL-6 protein in BW (table 4). Notably, a strong association was observed between the magnitude of the BW-MPO and BW-IL-8 responses $(\mathrm{r}=0.74$; $\mathrm{p}=0.002)$. The concentrations of these pro-inflammatory cytokines (IL-6 and IL-8) and the neutrophil degranulation product MPO were unaltered in the alveolar lavage sample $18 \mathrm{~h}$ after DE (table 4).

\section{Epithelial cell injury and altered permeability}

No increase was observed in airway permeability (total protein and albumin) or cell injury (DNA) in either the bronchial (BW) or alveolar (BAL) lavage fluid samples after DE (data not shown).

\section{Antioxidant responses}

A total of $18 \mathrm{~h}$ after the end of the DE exposure, significant increases were observed in both urate and reduced glutathione in alveolar lavage (0.78 post-air versus $1.07 \mu \mathrm{M}$ post-DE

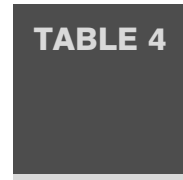

Soluble inflammatory mediators in bronchial wash (BW) and bronchoalveolar lavage (BAL) $18 \mathrm{~h}$ after a 2-h exposure to air and diesel exhaust (DE)

\begin{tabular}{|c|c|c|c|}
\hline $\begin{array}{l}\text { Inflammatory } \\
\text { mediators }\end{array}$ & Air & DE & p-value \\
\hline BW IL-6 pg·mL-1 & $4.0(1.4-4.9)$ & $4.9(2.6-7.0)$ & 0.06 \\
\hline BAL IL-6 pg $\cdot \mathrm{mL}^{-1}$ & $1.3(0.8-2.0)$ & $1.0(0.9-1.7)$ & 0.28 \\
\hline BW IL-8 pg.mL ${ }^{-1}$ & $35(15-65)$ & $45(35-140)$ & 0.01 \\
\hline BAL IL-8 pg $\cdot \mathrm{mL}^{-1}$ & $0.0(0.0-0.0)$ & $0.0(0.0-0.0)$ & 0.25 \\
\hline BW MPO $\mu \mathrm{g} \cdot \mathrm{L}^{-1}$ & $5.1(3.2-9.9)$ & $11.2(4.3-20.7)$ & 0.03 \\
\hline BAL MPO $\mu \mathrm{g} \cdot \mathrm{L}^{-1}$ & $0.0(0.0-1.4)$ & $1.7(0.0-2.1)$ & 0.11 \\
\hline
\end{tabular}

Data are presented as median (interquartile range). IL: interleukin; MPO: myeloperoxidase. $\mathrm{n}=15$. $(\mathrm{p}=0.03)$ and 0.33 post-air versus $0.46 \mu \mathrm{M}$ post-DE $(\mathrm{p}=0.03)$, respectively), whereas no effect in vitamin $\mathrm{C}$ (ascorbate and dehydroascorbate) was observed (table 5). In contrast, no change was seen in the concentration of urate, glutathione (GSH and GSSG) or vitamin C in bronchial lavage (table 5).

\section{DISCUSSION}

In the current study, the authors investigated the hypothesis that inflammatory responses in humans exposed to PM could be modulated by upregulation of antioxidant defences at the air-lung interface. Subjects were exposed to $100 \mu \mathrm{g} \cdot \mathrm{m}^{-3}$ of DE. Under the exposure conditions employed, the present authors observed neutrophil and mast cell recruitment into the bronchial airways $18 \mathrm{~h}$ after DE challenge. These cell influxes were not associated with any upregulation of VCAMs, suggesting the response had progressed beyond the recruitment phase. Increased concentrations of bronchial wash MPO were also observed, indicating neutrophil degranulation following the diesel challenge. In contrast, no alveolar inflammation was observed. Instead the alveolar response was characterised by the movement of GSH and urate into the airway lumen. These data demonstrate that DE causes bronchial inflammation, but suggest that the movement of GSH and urate onto the lung surface protects against inflammation in the alveolar region.

Human ambient particle exposure studies fall into two broad types, using either concentrated ambient particles (CAP) [3234] or DE, which may be either freshly generated DE (particles and associated gaseous components) [27-29] or re-aerosolised DEP [31]. Studies in which human volunteers have been exposed to CAP have yielded inconsistent results, with evidence that systemic inflammation may be more pronounced than pulmonary responses [32-34]. In contrast, pulmonary and systemic inflammatory responses have been reported in volunteers exposed to high concentrations of fresh $\mathrm{DE}$ $\left(300 \mu \mathrm{g} \cdot \mathrm{m}^{-3}\right.$ PM10, $1.6 \mathrm{ppm}$ nitric dioxide, $4.3 \mathrm{ppm}$ total hydrocarbons for $1 \mathrm{~h}$ with intermittent exercise) [28] or resuspended diesel particles $\left(200 \mu \mathrm{g} \cdot \mathrm{m}^{-3}\right.$ for $2 \mathrm{~h}$ at rest) [31]. In both studies, an early neutrophilia was seen $4-6 \mathrm{~h}$ postexposure in induced sputum and bronchial lavage, respectively $[28,31]$. However, in another study where alveolar lavage

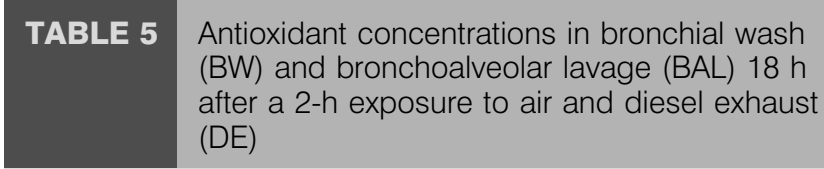

\begin{tabular}{lccc} 
Antioxidants $\boldsymbol{\mu M}$ & Air & DE & p-value \\
\hline BW vitamin C & $0.59(0.44-0.75)$ & $0.65(0.58-0.85)$ & 0.57 \\
BAL vitamin C & $0.51(0.37-0.70)$ & $0.62(0.44-0.74)$ & 0.23 \\
BW urate & $0.55(0.39-1.06)$ & $0.75(0.51-0.93)$ & 0.56 \\
BAL urate & $0.78(0.64-0.85)$ & $1.07(0.87-1.36)$ & 0.03 \\
BW GSH & $0.16(0.05-0.35)$ & $0.24(0.10-0.47)$ & 0.52 \\
BAL GSH & $0.33(0.20-0.45)$ & $0.46(0.24-0.74)$ & 0.04
\end{tabular}

Data are presented as median (interquartile range). GSH: reduced glutathione $n=15$. 
was also performed a similar neutrophil response was not seen in the alveolar region [28]. When these responses were examined at a lower concentration $\left(100 \mu \mathrm{g} \cdot \mathrm{m}^{-3}\right)$, the only significant changes seen $6 \mathrm{~h}$ post-exposure were increases in bronchial airway IL-6 and IL-8 protein, and upregulation of the vascular endothelial adhesion molecule P-selectin [29]. Despite the absence of increased airway neutrophils, these changes were interpreted as being indicative of an early inflammatory response. The present authors also observed evidence for a movement of GSH onto the bronchial and nasal airway surfaces, but not in alveolar lavage [17].

To distinguish whether the diminished response seen $6 \mathrm{~h}$ after the $100 \mu \mathrm{g} \cdot \mathrm{m}^{-3} \mathrm{DE}$ challenge was related to the evolution of a protective antioxidant response, the current authors repeated this exposure but examined airway responses after $18 \mathrm{~h}$. The rationale for this was to establish whether the response at $6 \mathrm{~h}$ was attenuated or simply delayed. As the PM in the chamber during the DE exposure was dominated by fine particles with a median mass diameter of $0.18 \mu \mathrm{m}$, the fractional particle deposition would have been low, but similar in conducting airways and alveoli [37]. However, due to the large surface area of the alveoli, the particle dose per unit surface area would be significantly less than in bronchial airways. Consequently, examining the balance between antioxidant and pro-inflammatory processes in these two regions permitted a comparison at different tissue doses.

A considerable body of evidence exists demonstrating that DEP are capable of inducing oxidative stress in vivo, largely related to their content of redox-active metals $[17,18]$ and quinones [16]. Mechanistically, this oxidative capacity has been proposed to drive the upregulation of pro-inflammatory cytokines through the activation of nuclear factor $\kappa \mathrm{B}[38,39]$. Consistent with this view, treatment of particle-challenged cells with antioxidants abolishes the production of a range of pro-inflammatory cytokines [19, 21, 38, 39]. Recent work has also illustrated that cells challenged with increasing concentrations of DEP elicit a hierarchical response, with protective antioxidant responses predominating at low concentrations, and inflammation and injury only occurring at high particle concentrations [36].

At the 6-h time point, the present authors observed a significant increase in GSH concentrations in both nasal and bronchial airway lavage samples after DE [17]. Despite this early mobilisation of GSH to the airway surface [17], inflammation was established (neutrophilia, degranulation and mastocytosis) $18 \mathrm{~h}$ after DE. In contrast, no inflammatory or antioxidant responses were seen $6 \mathrm{~h}$ post-diesel in the peripheral lung. Even $18 \mathrm{~h}$ post-exposure, no evidence of an increase in pro-inflammatory cytokines or inflammatory cells was seen in alveolar lavage, but GSH and urate concentrations were significantly increased. It seems unlikely that this reflects a delayed response in the alveoli as these antioxidant responses were seen in the absence of any upregulation of pro-inflammatory signals. Hence, the current authors conclude that the dose of particles penetrating to the peripheral lung in a diesel challenge of $100 \mu \mathrm{g} \cdot \mathrm{m}^{-3}$ was insufficient to elicit inflammation due to the predominance of protective antioxidant responses.
Similar increases in alveolar lavage urate have been reported following ozone exposures in humans [40,41] and animals [42]. This may reflect a movement of urate from the plasma pool, but no evidence of altered airway permeability was found to support this view. This increase in urate could also reflect increased synthesis by pulmonary cells, either as a consequence of increased adenosine metabolism or increased xanthine oxidase activity. Notably, increased lavage fluid urate concentrations have been reported in rats after intratracheal challenge with iron salts, associated with an increase in pulmonary xanthine oxidase activity [43]. Elevated concentrations of airway GSH have also been reported in numerous air pollutant studies [17, 44]. It has been speculated that this increase may reflect release from necrotic or apoptotic cells. However, the current authors saw no evidence of a reduction in any alveolar cell population. Therefore, it seems likely that the observed increase reflects an increased rate of glutathione synthesis, allied to increased export to the cell surface. Furthermore, in vitro incubation of macrophages with DEP has been shown to result in time-dependent increases in intracellular GSH and cysteine concentrations, as well as increased glutathione reductase activity [35].

In conclusion, these results, placed in the context of the earlier findings obtained $6 \mathrm{~h}$ after diesel exhaust [17], indicate clear regional differences in the response of the airway to diesel exhaust. Although reduced glutathione concentrations were increased in the bronchial airways $6 \mathrm{~h}$ after diesel exhaust, this response was insufficient to prevent the development of neutrophilia or mastocytosis $18 \mathrm{~h}$ post-exposure. In contrast, in the alveoli, where tissue particle doses were lower, no inflammation was apparent at either time point, while the response was characterised by protective antioxidant movements onto the airway surface. These responses lend in vivo support to the hierarchical response model proposed by XIAO et al. [36] and provide mechanistic data supporting the existence of a threshold for acute airway responses to diesel exhaust in humans.

\section{ACKNOWLEDGEMENTS}

The authors would like to thank A. Johansson, H. Tjällgren, H. Bertilsson, J. Pourazar, A-B. Lundström and M-C. Ledin for their technical contribution to this project. The authors would also like to thank the volunteers participating in this investigation.

\section{REFERENCES}

1 Atkinson RW, Anderson HR, Sunyer J, et al. Acute effects of particulate air pollution on respiratory admissions: results from APHEA 2 project. Air Pollution and Health: a European approach. Am J Respir Crit Care Med 2001; 164: Suppl. 10 Pt 1, 1860-1866.

2 Dockery DW, Pope CA 3rd, Xu X, et al. An association between air pollution and mortality in six U.S. cities. $N$ Engl J Med 1993; 329: 1753-1759.

3 Samet JM, Dominici F, Curriero FC, Coursac I, Zeger SL. Fine particulate air pollution and mortality in 20 U.S. cities, 1987-1994. N Engl J Med 2000; 343: 1742-1749.

4 Chow JC, Watson JG, Frazier CA, Egami RT, Goodrich A, Ralph C. Spatial and temporal source contributions to 
PM10 and PM2.5 in Reno, NV. In: Mathal CV, Stonefield DH, eds. Transactions, PM-10: Implementation of Standards. Pittsburgh, PA, Air and Waste Management Association 1988; pp. 437-439.

5 Japar SM. Motor vehicles and particle air pollution 1995: an overview. In: Particulate Matter: Health and Regulatory Issues VIP-49. Pittsburgh, PA, Air and Waste Management Association 1995; pp. 577-598.

6 Brunekreef B, Janssen NA, de Hartog J, Harssema H, Knape M, van Vliet P. Air pollution from truck traffic and lung function in children living near motorways. Epidemiology 1997; 8: 298-303.

7 van Vliet P, Knape M, de Hartog J, Janssen N, Harssema H, Brunekreef B. Motor vehicle exhaust and chronic respiratory symptoms in children living near freeways. Environ Res 1997; 74: 122-132.

8 English P, Neutra R, Scalf R, Sullivan M, Waller L, Zhu L. Examining associations between childhood asthma and traffic flow using a geographic information system. Environ Health Perspect 1999; 107: 761-767.

9 Oosterlee A, Drijver M, Lebret E, Brunekreef B. Chronic respiratory symptoms in children and adults living along streets with high traffic density. Occup Environ Med 1996; 53: 241-247.

10 Wjst M, Reitmeir P, Dold S, et al. Road traffic and adverse effects on respiratory health in children. BMJ 1993; 307: 596-600.

11 Nicolai T, Carr D, Weiland SK, et al. Urban traffic and pollutant exposure related to respiratory outcomes and atopy in a large sample of children. Eur Respir J 2003; 21: 956-963.

12 Weiland SK, Mundt KA, Ruckmann A, Keil U. Selfreported wheezing and allergic rhinitis in children and traffic density on street of residence. Ann Epidemiol 1994; 4: 243-247.

13 Janssen NA, Brunekreef B, van Vliet $P$, et al. The relationship between air pollution from heavy traffic and allergic sensitization, bronchial hyperresponsiveness, and respiratory symptoms in Dutch schoolchildren. Environ Health Perspect 2003; 111: 1512-1518.

14 Buckeridge DL, Glazier R, Harvey BJ, Escobar M, Amrhein C, Frank J. Effect of motor vehicle emissions on respiratory health in an urban area. Environ Health Perspect 2002; 110: 293-300.

15 Bonvallot V, Baulig A, Boland S, Marano F, Baeza A. Diesel exhaust particles induce an inflammatory response in airway epithelial cells: involvement of reactive oxygen species. Biofactors 2002; 16: 15-17.

16 Xia T, Korge P, Weiss JN, et al. Quinones and aromatic chemical compounds in particulate matter induce mitochondrial dysfunction: implications for ultrafine particle toxicity. Environ Health Perspect 2004; 112: 1347-1358.

17 Mudway IS, Stenfors N, Duggan ST, et al. An in vitro and in vivo investigation of the effects of diesel exhaust on human airway lining fluid antioxidants. Arch Biochem Biophys 2004; 423: 200-212.

18 Aust AE, Ball JC, $\mathrm{Hu} \mathrm{AA}$, et al. Particle characteristics responsible for effects on human lung epithelial cells. Res Rep Health Eff Inst 2002; 110: 1-65; discussion 67-76.

19 Baulig A, Garlatti M, Bonvallot V, et al. Involvement of reactive oxygen species in the metabolic pathways triggered by diesel exhaust particles in human airway epithelial cells. Am J Physiol Lung Cell Mol Physiol 2003; 285: L671-L679.

20 Han JY, Takeshita K, Utsumi H. Noninvasive detection of hydroxyl radical generation in lung by diesel exhaust particles. Free Radic Biol Med 2001; 30: 516-525.

21 Boland S, Bonvallot V, Fournier T, Baeza-Squiban A, Aubier M, Marano F. Mechanisms of GM-CSF increase by diesel exhaust particles in human airway epithelial cells. Am J Physiol Lung Cell Mol Physiol 2000; 278: L25-L32.

22 Seagrave J, Mauderly JL, Seilkop SK. In vitro relative toxicity screening of combined particulate and semivolatile organic fractions of gasoline and diesel engine emissions. J Toxicol Environ Health A 2003; 66: 1113-1132.

$23 \mathrm{Li} \mathrm{N}$, Wang M, Oberley TD, Sempf JM, Nel AE. Comparison of the pro-oxidative and proinflammatory effects of organic diesel exhaust particle chemicals in bronchial epithelial cells and macrophages. J Immunol 2002; 169: 4531-4541.

24 Sagai M, Furuyama A, Ichinose T. Biological effects of diesel exhaust particles (DEP). III. Pathogenesis of asthmalike symptoms in mice. Free Radic Biol Med 1996; 21: 199-209.

25 Nikula KJ, Avila KJ, Griffith WC, Mauderly JL. Sites of particle retention and lung tissue responses to chronically inhaled diesel exhaust and coal dust in rats and cynomolgus monkeys. Environ Health Perspect 1997; 105, Suppl. 5, 1231-1234.

26 Takano H, Yanagisawa R, Ichinose $T$, et al. Diesel exhaust particles enhance lung injury related to bacterial endotoxin through expression of proinflammatory cytokines, chemokines, and intercellular adhesion molecule-1. Am J Respir Crit Care Med 2002; 165: 1329-1335.

27 Rudell B, Blomberg A, Helleday R, et al. Bronchoalveolar inflammation after exposure to diesel exhaust: comparison between unfiltered and particle trap filtered exhaust. Occup Environ Med 1999; 56: 527-534.

28 Salvi S, Blomberg A, Rudell B, et al. Acute inflammatory responses in the airways and peripheral blood after shortterm exposure to diesel exhaust in healthy human volunteers. Am J Respir Crit Care Med 1999; 159: 702-709.

29 Stenfors N, Nordenhall C, Salvi SS, et al. Different airway inflammatory responses in asthmatic and healthy humans exposed to diesel. Eur Respir J 2004; 23: 82-86.

30 Holgate ST, Sandstrom T, Frew AJ, et al. Health effects of acute exposure to air pollution. Part I: Healthy and asthmatic subjects exposed to diesel exhaust. Res Rep Health Eff Inst 2003; 112: 1-30; discussion 51-67.

31 Nightingale JA, Maggs $\mathrm{R}$, Cullinan $\mathrm{P}$, et al. Airway inflammation after controlled exposure to diesel exhaust particulates. Am J Respir Crit Care Med 2000; 162: 161-166.

32 Holgate ST, Devlin RB, Wilson SJ, Frew AJ. Health effects of acute exposure to air pollution. Part II: Healthy subjects exposed to concentrated ambient particles. Res Rep Health Eff Inst 2003; 112: 31-50; discussion 51-67.

33 Ghio AJ, Kim C, Devlin RB. Concentrated ambient air particles induce mild pulmonary inflammation in healthy human volunteers. Am J Respir Crit Care Med 2000; 162: Suppl. 3 Pt 1, 981-988.

34 Gong H Jr, Sioutas C, Linn WS. Controlled exposures of healthy and asthmatic volunteers to concentrated ambient 
particles in metropolitan Los Angeles. Res Rep Health Eff Inst 2003; 118: 1-36; discussion 37-47.

35 Al-Humadi NH, Siegel PD, Lewis DM, et al. Alteration of intracellular cysteine and glutathione levels in alveolar macrophages and lymphocytes by diesel exhaust particle exposure. Environ Health Perspect 2002; 110: 349-353.

36 Xiao GG, Wang M, Li N, Loo JA, Nel AE. Use of proteomics to demonstrate a hierarchical oxidative stress response to diesel exhaust particle chemicals in a macrophage cell line. J Biol Chem 2003; 278: 50781-50790.

37 Gerrity TR. Regional deposition of gases and particles in the lung: implications for mixtures. Toxicology 1995; 105: 327-334.

38 Takizawa H, Ohtoshi T, Kawasaki S, et al. Diesel exhaust particles induce NF-kappa B activation in human bronchial epithelial cells in vitro: importance in cytokine transcription. J Immunol 1999; 162: 4705-4711.

39 Bonvallot V, Baeza-Squiban A, Baulig A, et al. Organic compounds from diesel exhaust particles elicit a proinflammatory response in human airway epithelial cells and induce cytochrome p450 1A1 expression. Am J Respir Cell Mol Biol 2001; 25: 515-521.

40 Koren HS, Devlin RB, Graham DE, et al. Ozone-induced inflammation in the lower airways of human subjects. Am Rev Respir Dis 1989; 139: 407-415.

41 Jorres RA, Holz O, Zachgo W, et al. The effect of repeated ozone exposures on inflammatory markers in bronchoalveolar lavage fluid and mucosal biopsies. Am J Respir Crit Care Med 2000; 161: 1855-1861.

42 Kirschvink N, Fievez L, Bureau F, et al. Adaptation to multiday ozone exposure is associated with a sustained increase of bronchoalveolar uric acid. Free Radic Res 2002; 36: 23-32.

43 Ghio AJ, Kennedy TP, Stonehuerner J, et al. Iron regulates xanthine oxidase activity in the lung. Am J Physiol Lung Cell Mol Physiol 2002; 283: L563-L572.

44 Blomberg A, Mudway IS, Nordenhall C, et al. Ozoneinduced lung function decrements do not correlate with early airway inflammatory or antioxidant responses. Eur Respir J 1999; 13: 1418-1428. 